\title{
CONSIDERATION UPON FIXED ANTI - ROLLING PASSIVE SYSTEMS
}

\author{
lordan NOVAC ${ }^{1}$ \\ Catalin FAITAR ${ }^{2}$ \\ 1 Associate Professor Eng., Constanta Maritime University \\ 2 Eng., Constanta Maritime University
}

\begin{abstract}
Tanks anti - rolling Passive Systems, are those systems which have no separate source of movement and no special automatic control system like the Bilge keel, anti - rolling tanks (passive), fixed fins and passive moving weight system. For a vessel, roll motion has the highest amplitude at resonance (this motion is known as synchronous rolling). From the research done so far, the best thing to reduce this movement is increasing amortization. There are many ways to reduce roll motions, and the most known is equipping the vessel with bilge keels. If ship requires more control, there are methods such as anti-roll tanks and fins. Tanks have the advantage of functioning when the ship is not underway. The use of tanks with liquid free surfaces for reducing roll motion of ships is an old concept. Many research engineers have studied the design of anti-roll tanks. However, most of the past research has concentrated on studying the randament of anti-roll tanks in damping the roll motion of the vessel.
\end{abstract}

Keywords: roll motion, tanks, passive, fin, keel

\section{Introduction}

Reducing rolling motion is one of the most desired shipbuilders requirements. Because of this, there are a lot of reductions systems for ships amplitude and movement acceleration that act on its dynamical effect attenuation. In anti - rolling amortization systems study is all important to know forces values applied for getting an emphatic amplitude and acceleration reducing.From all oscillations type (vertical, pitching, rolling, etc.), through this moment can be successfully damped only anti - rolling motion because required moments are small, against the other ones.

For oscillation amortization there are three main type of constrained motion reductions:

- By rising ship amortization factor. This way means a destruction of energy and is referring to free oscillations for resonance area where is maximum effective power. For this category, we have anti rolling fins and bilge keel.

- By reducing natural frequency of ship and cycle rising. This stabilization type is named ,,according amortization" and is applied only in constrained oscillations where we have a big variation of frequency.

- By direct reducing forces and moments of excitation. This stabilization type is named ,,equilibration stabilization" where applied moment is against perturbation moment. Because of this, the main moment is reduced. Also, stabilization system efficiency depends on the control system.

\section{Anti - rolling passive tanks}

The use of these tanks was implemented by Frahm in Germany at the start of the 20th century, and they are often referred to as Frahm tanks. These semi filled tanks consist of two wing tanks connected at the bottom by a substantial crossover pipe. The air columns above the liquid in the two tanks are also connected by a pipe. As in the free surface tanks, as the ship starts to roll the fluid flows from wing tank to wing tank causing a time varying roll moment to the ship and with a careful design this rolling moment is of correct phasing to reduce the roll motion of the vessel. They do not restrict fore, and aft passage as space above and below the water-crossover pipe is available for other purposes.

There are several types of roll damping systems that have been developed to reduce a vessel's roll motion during operation at sea. Passive roll damping tanks, also referred to as passive antiroll tanks, use a hydro-dynamically controlled flow of liquid within a specially designed tank, filled with ballast water, to create a stabilizing moment opposing the wave moment that is causing the vessel to roll. The amount of stabilizing moment created depends on several factors, such as size and location of the roll damping tank as well as hull form and loading condition of the vessel. Generally, with a passive roll damping tank an average roll reduction between $40 \%$ to $60 \%$ can be achieved.

The U-Tank Stabilization System is individually designed for each specific application. A number of tanks, proper dimensions, shape, location, internal structure and volume, are varied to match each type of vessel and operating condition. 
"Mircea cel Batran" Naval Academy Scientific Bulletin, Volume XIX - 2016 - Issue 2

The journal is indexed in: PROQUEST / DOAJ / Crossref / EBSCOhost / INDEX COPERNICUS / DRJI / OAJI I JOURNAL INDEX I I2OR / SCIENCE LIBRARY INDEX / Google Scholar / Academic Keys/ ROAD Open Access I Academic Resources / Scientific Indexing Services / SCIPIO / JIFACTOR

When correctly designed the liquid flow within the tank will naturally lag behind the resonant roll motion of the vessel by $90^{\circ}$. This means the tank will create a stabilizing force directly opposing the forces created by the passing wave.

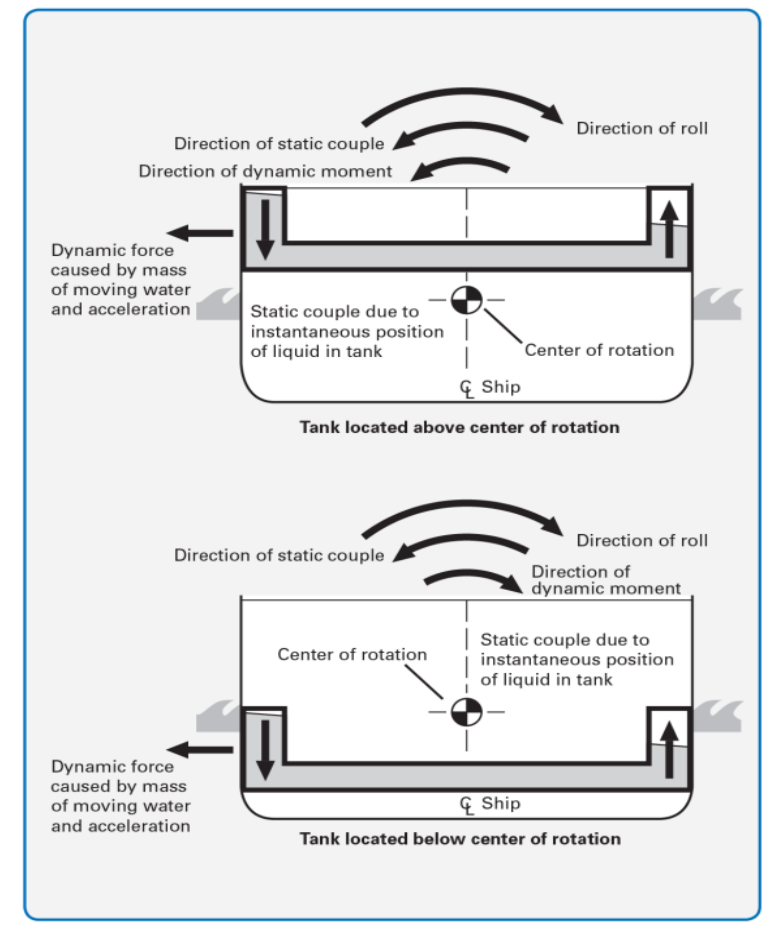

Figure 1. Antirooling passive tanks

The stabilizers are installed on various types of vessels from $20 \mathrm{~m}$ up to $400 \mathrm{~m}$ length:

- Offshore Support (PSV, AHTS, DSV) vessel

- Offshore Construction vessel

- RORO / ROPAX vessel

- Container vessel

- Research vessel

- Pipe Lay vessel

- Buoy Tender vessel

- Fishing vessel

- Naval

A U-Tank Stabilization System is a passive U-tube type anti-roll tank combined with monitoring and an active control system. The stabilizer consists of two wing tanks interconnected via a crossover pipe either through or above the double bottom and a closed air pipe system including remotely operated valves. The fluid flow within the stabilizer is used to create a stabilizing moment reducing the roll motion of the vessel, hence decreasing roll angles and accelerations. The stabilizer's dimensions and structural boundaries determine its natural response period which has to be close to the expected shortest roll period of the vessel. A change of the response period is achieved by restricting the air flow. The system automatically controls the remotely operated valves to adapt the water oscillation period to the measured actual roll period of the vessel. 
"Mircea cel Batran" Naval Academy Scientific Bulletin, Volume XIX - 2016 - Issue 2

The journal is indexed in: PROQUEST I DOAJ / Crossref / EBSCOhost / INDEX COPERNICUS I DRJI / OAJI I JOURNAL INDEX I I2OR / SCIENCE LIBRARY INDEX / Google Scholar / Academic Keys/ ROAD Open Access I Academic Resources / Scientific Indexing Services / SCIPIO / JIFACTOR

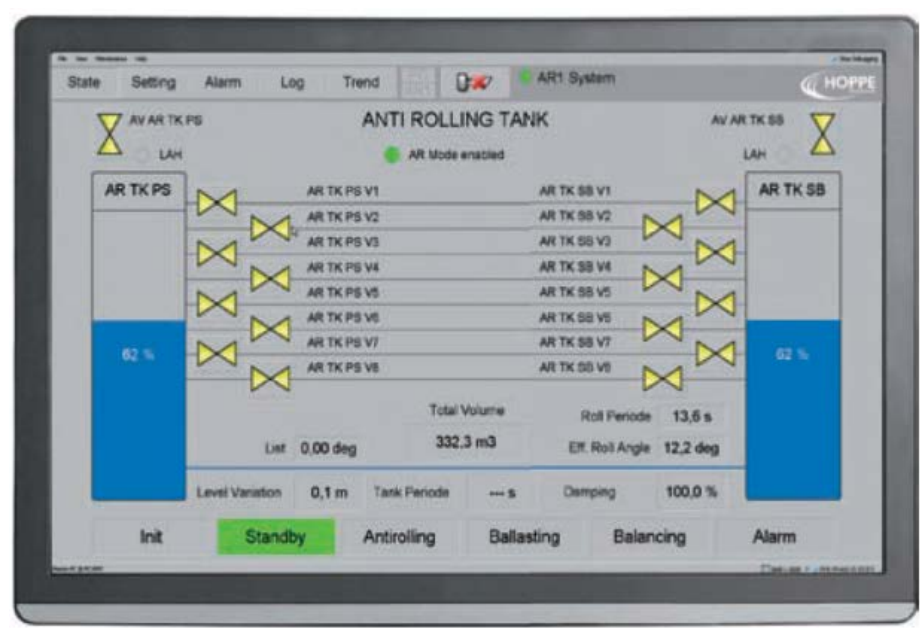

Figure 2. Antirooling passive tanks system

The monitoring and control system has been developed to operate the U-Tank stabilizer safe and with high efficiency in all operation conditions. The control unit type HOMIP contains the software package for processing of data from the roll sensor unit, the tank pressure sensors, level switches and valve positions. The system monitors permanently the vessel and tank movement as well pressure and level inside tank to act accordingly roll damping performance and safety. The actual system status is displayed in 6" HOMIP touch screen and on larger touch screens in control cabinet and bridge operation panel.

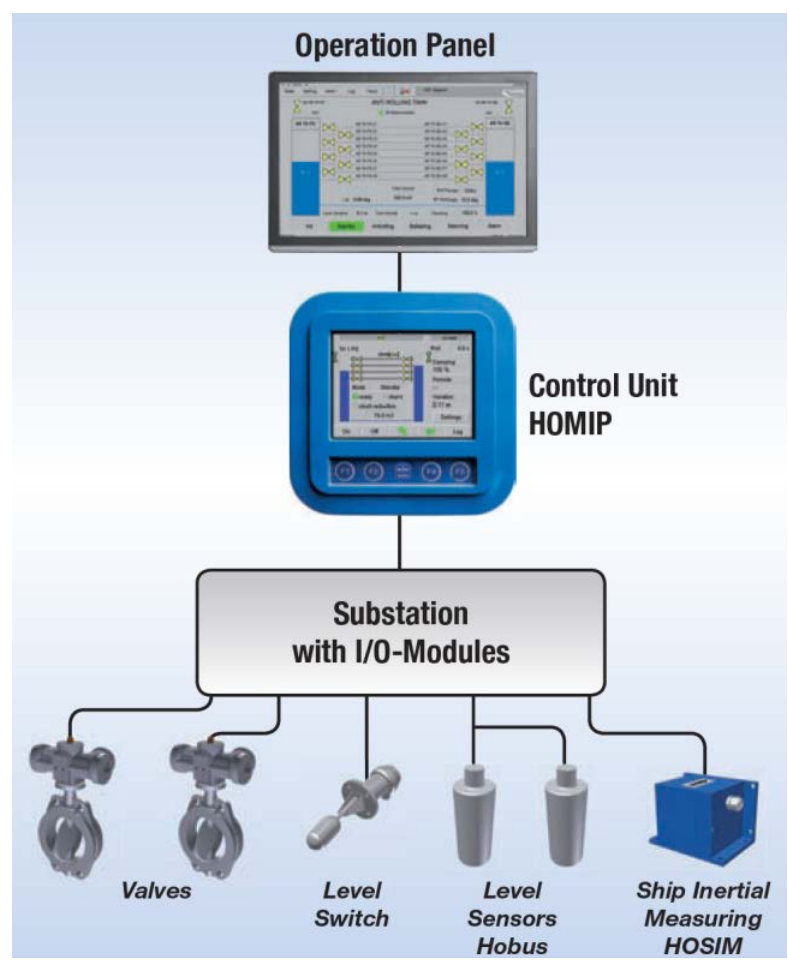

Figure 3. Antirooling passive tanks control system

\section{Fixed fins}

Fixed fins and bilge keels do not move; they reduce roll by hydrodynamic drag exerted when the vessel rolls. Stabilizers are mostly used on ocean-going (blue water) vessels. Not only retractable fins but also fixed fins are calculated and are mounted on vessel body like pairs (starboard - port side). Depending on the 
"Mircea cel Batran" Naval Academy Scientific Bulletin, Volume XIX - 2016 - Issue 2

The journal is indexed in: PROQUEST / DOAJ / Crossref / EBSCOhost / INDEX COPERNICUS / DRJI / OAJI I JOURNAL INDEX / I2OR / SCIENCE LIBRARY INDEX / Google Scholar / Academic Keys/ ROAD Open Access I Academic Resources / Scientific Indexing Services / SCIPIO / JIFACTOR

necessary area of anti - rolling fins, a vessel can have one or two pairs. If we have just one pair of fins, these are placed after 2/3 of vessel length, but when we have two pairs, the first pair is placed near $1 / 3$ of vessel length and second pair is placed after $2 / 3$ of vessel length. Fixed antirooling fins are calculated and mounted such as not be bigger than vessel width, and vessel keel deep. In figure 4 we have a hydrodynamic fin with a , $\mathrm{v}$ " speed against water. When fixed has a ,a" value of alist angle, we have two different speed on fin faces and also different pressures. Finally, we have a resulting „,P" pressure applied in , $\mathrm{O}$ " pressure center.
$P_{x}$ - profile resistance

$P_{n}-$ normal component

$P_{\text {t }}-$ tangential component

$P$ - total pressure

$$
\begin{gathered}
P=\sqrt{P_{y}^{2}+P_{x}^{2}}=\sqrt{P_{n}^{2}+P_{t}^{2}} \\
P_{\mathrm{n}}=P_{y} \cos \alpha+P_{x} \sin \alpha \\
P_{\mathrm{t}}=P_{x} \cos \alpha-P_{y} \sin \alpha
\end{gathered}
$$

$M_{y}$-axis fin moment

$$
M_{r}=P_{n}(e-d)
$$

$M$-attack moment

$$
M=P_{n} \times e
$$

$P_{y}$ - profile portant force

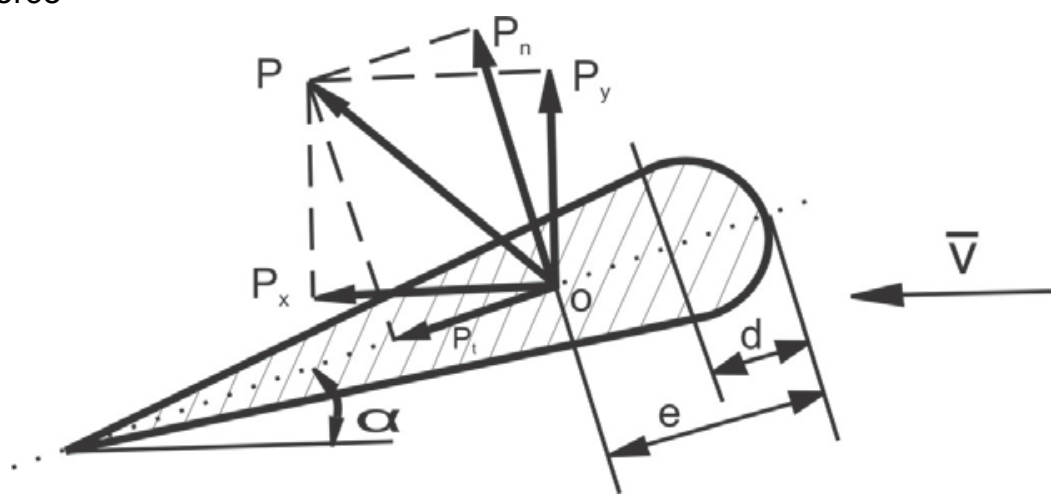

Figure 4. Passive fin forces

\section{Bilge keel}

A bilge keel is a long fin of metal, often in a " $\mathrm{V}$ " shape, welded along the length of the vessel at the turn of the bilge. Bilge keels are used in pairs (one for each side of the vessel). A vessel may have more than one bilge keel per side, but this is rare. Bilge keels increase the hydrodynamic resistance when a vessel rolls, thus limiting the amount of roll a vessel has to endure.
On commercial shipping the bilge keel is the form of a strake, or small keel or blister, running along much of the length of the hull. They are typically fitted one on each side, low down on the side of the hull, so as not to increase the draft of the vessel. In warships they were often quite large and used as part of the torpedo protection system. 
"Mircea cel Batran" Naval Academy Scientific Bulletin, Volume XIX - 2016 - Issue 2 The journal is indexed in: PROQUEST I DOAJ / Crossref / EBSCOhost / INDEX COPERNICUS / DRJI / OAJI I JOURNAL INDEX I I2OR / SCIENCE LIBRARY INDEX / Google Scholar / Academic Keys/ ROAD Open Access I Academic Resources / Scientific Indexing Services / SCIPIO / JIFACTOR

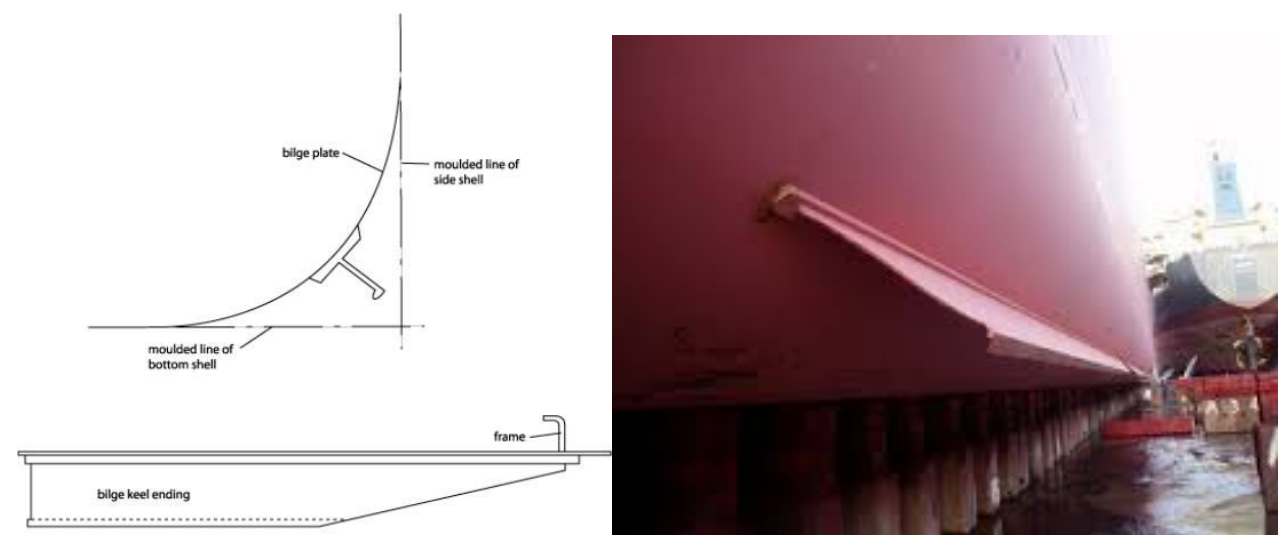

Figure 5. Bilge keel

\section{Moving weight system}

In a passive system, moving mass makes natural pendulum motions on the arc-shaped rails when the vessel rolls. This generates forces opposing the wave forces to reduce the roll of the vessel. In an active system, the weight is accurately controlled by electric motors according to information on lateral rolling detected by sensors to reduce the roll of the vessel. The hybrid system combines the features of the pendulum principle (passive system) and electric motor control (active system) to provide excellent roll control for low power expenditure.

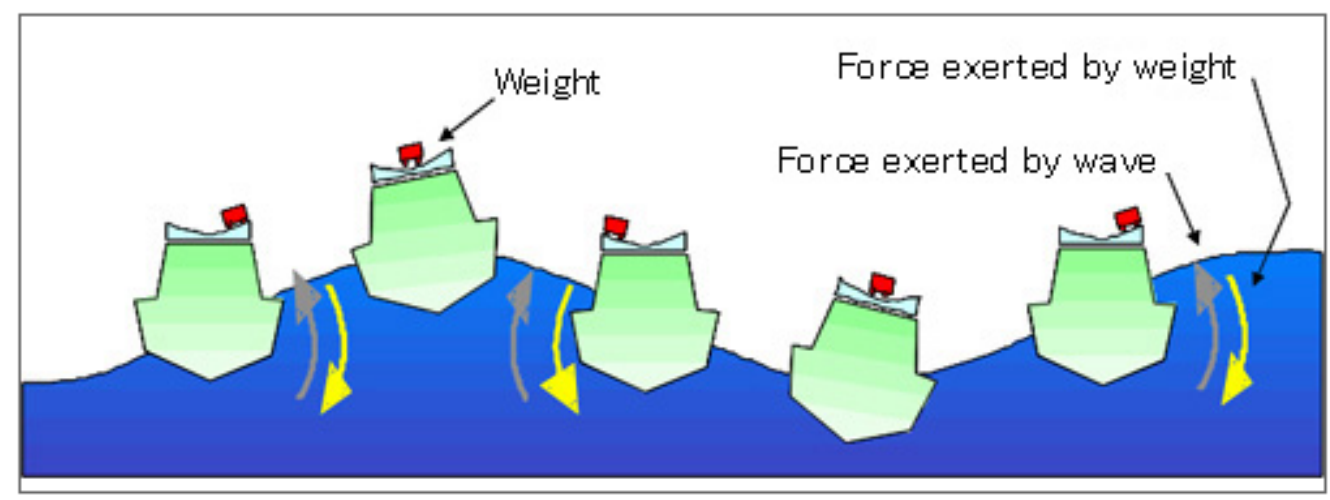

Figure 6. Moving weight system 
"Mircea cel Batran" Naval Academy Scientific Bulletin, Volume XIX - 2016 - Issue 2 The journal is indexed in: PROQUEST / DOAJ / Crossref / EBSCOhost / INDEX COPERNICUS / DRJI / OAJI / JOURNAL INDEX / I2OR / SCIENCE LIBRARY INDEX / Google Scholar / Academic Keys/ ROAD Open Access I Academic Resources / Scientific Indexing Services / SCIPIO / JIFACTOR

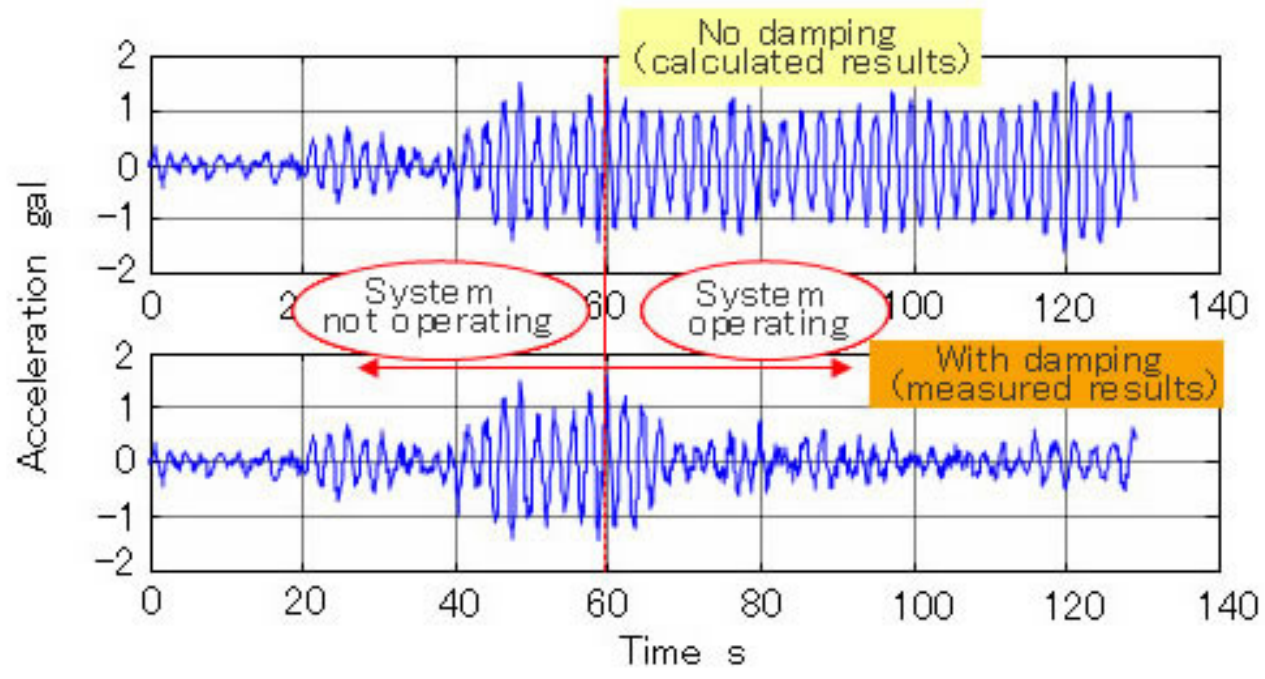

(a) Bending component (X direction)

Figure 7. Moving weight system acceleration diagram

Transversal oscillation of a $12000 \mathrm{t}$ vessel

We calculate moment of inertia:

$$
I_{x x}=\Delta \cdot i_{x x}^{2}=12000 \cdot 6^{2}=4,32 \cdot 10^{5}\left[\mathrm{tm}^{2}\right](6)
$$

- $\Delta=12000 t$ - vessel displacement;

- $i_{x x}=6 m$ - the radius of inertia around the longitudinal axis;

Total moment of inertia with extra vessel mass:

- $I_{x x 1}=(1+f) \cdot I_{x x}=5,184 \cdot 10^{5}\left[\mathrm{tm}^{2}\right]$

- $f=15 \%$ - water extra mass from vessel mass

For undamped oscilations we have following coefficients:

Proper pulsation for undamped oscillations:

$$
p_{\varphi}=\sqrt{\frac{g \cdot \overline{G M}_{T}}{(1+f) \cdot i_{x x}^{2}}}=\sqrt{\frac{9,81 \cdot 1,6}{1,15 \cdot 6^{2}}}=0,603 s^{-1}(
$$

Period of rolling undamped oscillations:

$$
T_{\varphi}=\frac{2 \pi}{p_{\varphi}}=\frac{2 \pi}{0,603}=10,425 \mathrm{~s}(9)
$$

For damped oscillations is necessary to calculate follows:

Damping factor $v_{\varphi}$ :

$v_{\varphi}=\frac{N_{\varphi}}{2 \cdot I_{x x 1}}=\frac{80000}{2 \cdot 5,184 \cdot 10^{5}}=0,077 s^{-1}$

where $2 N_{\varphi}=80000 \frac{\mathrm{tm}^{2}}{\mathrm{~s}}$ - damping coefficient

for navigation in calm water.

Pulsation of transversal oscillations, free, undamped:

$$
p_{\varphi r}=\sqrt{p_{\varphi}^{2}-v_{\varphi}^{2}}=0,598 s^{-1}
$$

Damped oscillations period: 
"Mircea cel Batran" Naval Academy Scientific Bulletin, Volume XIX - 2016 - Issue 2

The journal is indexed in: PROQUEST / DOAJ / Crossref / EBSCOhost / INDEX COPERNICUS / DRJI / OAJI I JOURNAL INDEX I I2OR / SCIENCE LIBRARY INDEX / Google Scholar / Academic Keys/ ROAD Open Access I Academic Resources / Scientific Indexing Services / SCIPIO / JIFACTOR

$$
T_{\varphi r}=\frac{2 \pi}{p_{\varphi r}}=\frac{2 \pi}{0,603}=10,512 \mathrm{~s}
$$

Logarithmic decrement:

$$
\Delta=v_{\varphi} \cdot \frac{2 \pi}{p_{\varphi}}=0,077 \frac{2 \pi}{0,603}=0,811
$$

Oscillations amplitude after one period:

$$
\varphi_{A 1}=e^{-n \cdot \Delta} \varphi_{A 0}=e^{-1 \cdot 0,811} \cdot 15^{0}=6,665^{0}
$$

\section{CONCLUSIONS}

From the above observation, it can be concluded that each and every stabilization system has got advantages and disadvantages. Therefore, more amount of effort has to be given to the hydrostatics and the hydrodynamics of the vessel hull motion through the waves, so as to avoid the need for kind of roll stabilization system or to use it to its minimum. Also, in principle methods used to stabilize against roll can be used to stabilize against pitch, but the powers involved are too great to justify their use.

Table 1.Passive anti - rolling system efficiency

\begin{tabular}{|c|c|c|c|c|}
\hline Type & Passive tanks & Fixed fins & Bilge keel & Moving weight \\
\hline Percentage roll reduction & $60-70 \%$ & $30 \%$ & $35 \%$ & $65 \%$ \\
\hline Effective at very low speeds & Yes & Yes & Yes & Yes \\
\hline Increase in vessel resistence & No & No & No & No \\
\hline Auxiliary power requirement & Nil & Nil & Nil & Nil \\
\hline Vulnerable to damage & No & Yes & Yes & No \\
\hline First cost & Moderate & Low & Low & High \\
\hline Maintenance & Low & Often high & Often high & High \\
\hline
\end{tabular}

\section{BIBLIOGRAPHY}

[1] Novac I.Ship theory andconstructionPart2- Ship hydrodynamics1,Constanta Maritime University, 2013

[2] Novac I.Ship theory and construction. Practical problems and guidelines for hydrostatics and hydrodynamics ship design, Constanta Maritime University, 2013

[3] Kula K.S.An Overview of Roll Stabilizers and Systems for Their Control, Gdynia Maritime University, Poland

[4] Agarwal A. Robust control technology applied to the design of a combined steering/ stabilizer system for warships, 1997

[5] Roberts G.N. Trends In Marine control systems, 2008

[6] www.hoppe-marine.com,U-Tank Stabilization System, Hoppe Korea Co., Ltd.

[7] www.deepdyve.com, Ship's roll stabilization by anti-roll active tanks

[8] Moaleji R. and Greig A. Inverse control for roll stabilization on ships using active tanks,2006

[9] Moaleji R. and Greig A. On the development of ship anti-roll tank,2007. 